\title{
"Still crazy after all these years" - Tuberculosis as an Old Disease with Diverse Facets in a Thirty-five-year-old Male Patient

\author{
“Still crazy after all these years” - die „alte Dame“ Tuberkulose mit ihren \\ verschiedenen Facetten bei einem 35-jährigen Patienten
}

Authors

Institutions
U. Knoop ${ }^{1}$, J. W. Dietrich², C. M. Heyer ${ }^{3}$, A. Koch ${ }^{1}$, H. Knoop ${ }^{1}$

Institutions are listed at the end of article. received 15.10 .2013

accepted 22.10.2013

Bibliography

DOI http://dx.doi.org/

10.1055/s-0033-1358910

Published online: 3.12.2013

Pneumologie 2014; 68: 206-207

(c) Georg Thieme Verlag KG

Stuttgart · New York

ISSN 0934-8387

\section{Corresponding author}

Dr. med. Heiko Knoop

Department of Internal Medicine

III - Respiratory and Sleep

Medicine, Allergology

Berufsgenossenschaftliches

Universitaetsklinikum

Bergmannsheil GmbH

Ruhr-University of Bochum

Buerkle-de-la-Camp-Platz 1,

44789 Bochum

Germany

Heiko.Knoop@ruhr-uni-

bochum.de

\section{Abstract \\ $\nabla$}

We report about a thirty-five-year-old male patient with miliary $\mathrm{TB}$ as first manifestation of HIV-infection.

\section{The Case}

$\nabla$

A thirty-five-year-old black male patient (BMI $21.1 \mathrm{~kg} / \mathrm{m}^{2}$ ) was transferred to our hospital for further treatment of miliary tuberculosis (TB) which had been diagnosed elsewhere. Besides hepatomegalia due to confirmed tuberculotic affection, a CT scan showed enlarged mediastinal and abdominal lymph nodes with features of central necrosis and multiple disseminated pulmonary and splenic lesions ( Fig. 1-3). HIV testing was positive, most likely as a consequence of unsafe sexual contacts with changing partners during a long-term stay in his home-country Kenya. Therefore, due to 1) HIV infection, 2) tuberculosis as acquired immune deficiency syndrome (AIDS)defining disease and 3) a CD4-cell count of 30 per $\mu$ l AIDS in CDC category C3 was diagnosed [1]. Standard antituberculotic treatment consisting of isoniazide $(\mathrm{H})$, rifampicine $(\mathrm{R})$, ethambutole (E) and pyrazinamide (Z) [2] had been paused at the time of admission to our hospital due to elevation of liver enzymes. Consequently, first sputum samples obtained in our hospital showed smearpositive pulmonary TB. Later on, the cultural result showed Mycobacterium tuberculosis (MTB) multisensitive to the antituberculotic medication mentioned above. We restarted treatment with $\mathrm{E}$ and replaced $\mathrm{R}, \mathrm{Z}$ and $\mathrm{H}$ by levofloxacin (LFX), streptomycin (SM) and rifabutin (RFB). As to lymph node enlargement, lymphoma as well as Pneumocystis jiroveci (PCJ)-pneumonia as additional AIDS-defining diseases was excluded. Meanwhile, bone marrow samples indicated additional TB-affection ( $\bullet$ Fig.4). Under treatment with SM for 30 days, LFX, RFB and E sputum

\section{Zusammenfassung \\ $\nabla$}

Wir berichten über einen 35-jährigen Patienten mit Miliartuberkulose als Erstmanifestation einer HIV-Infektion.

samples were negative for MTB. Blood samples showed rising CD4-cell count and 1734015 copies of HIV-1 per ml. After patient's transfer to a specialized department for AIDS, antituberculotic medication could be switched to RFB, E, Z and $\mathrm{H}$ with sustained success concerning microbiological results and stable laboratory liver parameters. Antiretroviral treatment with efavirenz, emtricitabine, and tenofovir was initiated. After four months of therapy, antituberculotic treatment could be reduced to RFB and $\mathrm{H}$.

Before admission to our hospital electrolyte imbalance with severe hyponatremia had been observed. Retrospectively, they were most likely due to syndrome of inadequate antidiuretic hormone secretion (SIADH) as TB-related phenomenon [3]. However, this assumption could not be verified, since levels of electrolytes and Copeptin A, a new biomarker for SIADH [4], were normalized at time of admission to our department. Copeptin has been evaluated as prognostic biomarker in community acquired-pneumonia $[5,6]$, but its diagnostic value in SIADH in the context of infectious diseases might be limited to a narrow time slot.

\section{Conclusion}

We present a case of extended miliary TB in a black male patient with African migration background and HIV infection as sexual transmitted disease (STD) and TB favouring disease. 


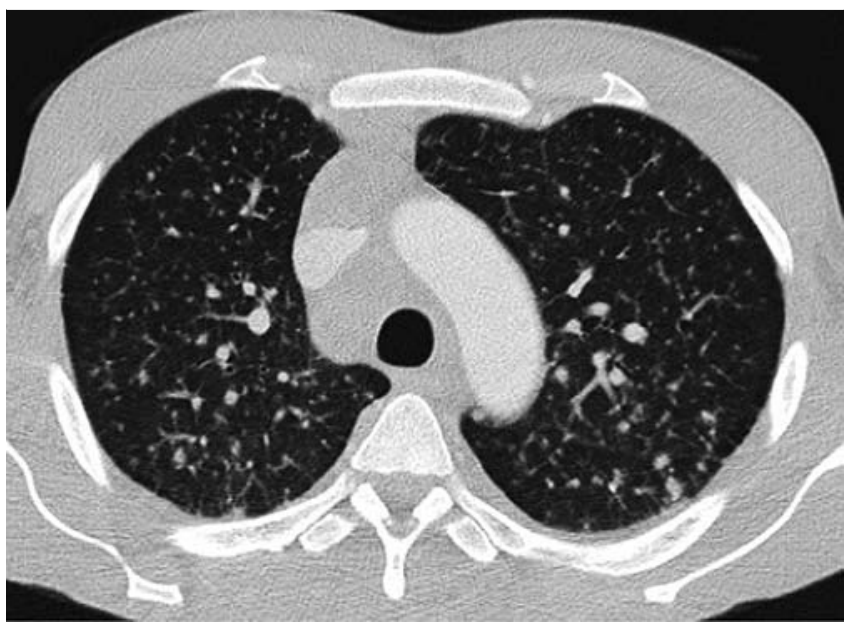

Fig. 1 Transverse CT scan of the chest shows multiple small nodules in both lungs.



Fig. 2 Contrast-enhanced CT displays enlarged hilar and mediastinal lymph nodes (arrows).

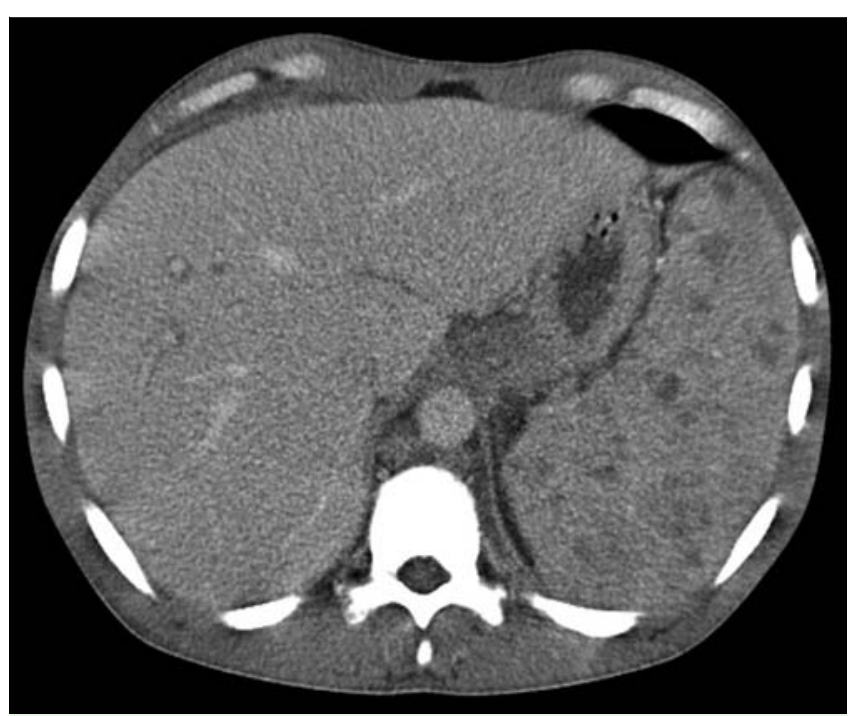

Fig. 3 Contrast-enhanced CT of the upper abdomen shows multiple small hypodense lesions within the enlarged spleen.

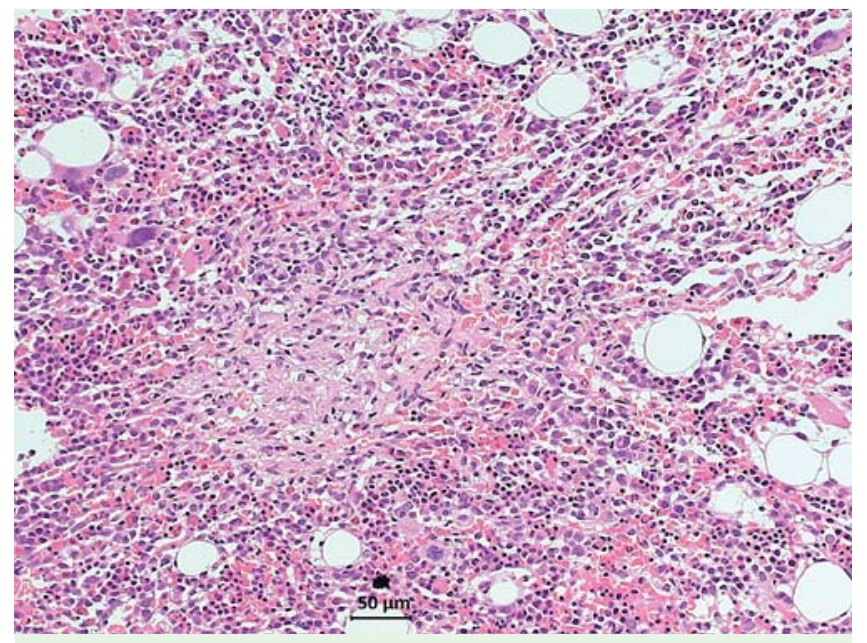

Fig.4 Bone marrow sample with nearly regular hematopoiesis, augmented number of T-cells and epithelioid cell graloma. Further testing did not confirm T-cell lymphoma.

\section{Acknowledgement}

$\nabla$

The authors would like to thank Professor Dr. Andrea Tannapfel for providing the histological figure.

\section{Conflict of Interest \\ $\nabla$ \\ The authors have no conflict of interest.}

\section{Institutions}

Department of Internal Medicine III - Respiratory Medicine,

Berufsgenossenschaftliches Universitaetsklinikum Bergmannsheil GmbH, Ruhr-University of Bochum, Germany

Department of Internal Medicine I - Internal Medicine, Diabetology and Endocrinology, Berufsgenossenschaftliches Universitaetsklinikum Bergmannsheil GmbH, Ruhr-University of Bochum, Germany

Institute of Diagnostic Radiology, Interventional Radiology and Nuclear Medicine, Berufsgenossenschaftliches Universitaetsklinikum Bergmannsheil $\mathrm{GmbH}$, Ruhr-University of Bochum, Germany

\section{References}

1 Schneider E, Whitmore S, Glynn KM et al. Revised surveillance case definitions for HIV infection among adults, adolescents, and children aged $<18$ months and for HIV infection and AIDS among children aged 18 months to $<18$ years - United States, 2008. MMWR Recomm Rep 2008; 57: $1-12$

2 Schaberg T, Bauer T, Castell S et al. Recommendations for therapy, chemoprevention and chemoprophylaxis of tuberculosis in adults and children. German Central Committee against Tuberculosis (DZK), German Respiratory Society (DGP). Pneumologie 2012; 66: 133-171

3 Knoop H, Knoop U, Behr J et al. Syndrome of inadequate antidiuretic hormone secretion in pulmonary tuberculosis - a therapeutic challenge. Pneumologie 2013; 67: 219-222

4 Fenske W, Störk S, Blechschmidt A et al. Copeptin in the differential diagnosis of hyponatremia. J Clin Endocrinol Metab 2009; 94: 123 -9

5 Kolditz M, Halank M, Schulte-Hubbert B et al. Copeptin predicts clinical deterioration and persistent instability in community-acquired pneumonia. Respir Med 2012; 106: 1320-1328

6 Kolditz M, Ewig S, Höffken G. Management-based risk prediction in community-acquired pneumonia by scores and biomarkers. Eur Respir J 2013; 41: 974-984 